\title{
Örgütsel Zekâ Düzeyinin Öğretmenlerin Yenilikçi Çalışma Davranışları Üzerindeki Etkisi ${ }^{1}$
}

\author{
DOI: 10.26466/opus.937986
}

\author{
Belgin Tura* $^{*}$ Sait Akbaşl1 ${ }^{* *}$ \\ * Öğretmen, Melikşah Ortaokulu, Ankara/Türkiye \\ E-Posta: belgintura@gmail.com \\ ORCID: $\quad$ 0000-0001-9120-7928 \\ ** Prof. Dr, Hacettepe Üniversitesi, Ankara/Türkiye \\ E-Posta: sakbasli@gmail.com \\ ORCID: $\quad$ 0000-0001-9406-8011
}

$\ddot{O} z$

$B u$ araştırma, okulların örgütsel zekâ düzeyinin öğretmenlerin yenilikçi çalışma davranışları üzerindeki etkisinin belirlenmesi amacıyla yapılmıştır. Araştırmanın çalışma grubu, uygun örnekleme yöntemi ile tespit edilen, 2020-2021 eğitim öğretim yılında Ankara ili Sincan İlçe Milli Ĕ̆itim Müdürlü̆̆̈̈'ne bağll kamu ortaokulu ve imam hatip ortaokullartnda görevli 328 branş öğretmenidir. Araştırmada, Çok Boyutlu Örgütsel Zekâ Ölçeği ve Yenilikçi Çalışma Davranışı Ölçeğgi kullanılmıştır. Araştırma verilerinin analizinde betimsel istatistikler ile öğretmenlerin görev yaptıkları okulların örgütsel zekâ düzeyinin yenilikçi çalışma davranışlarının anlamlı bir yordayıcısı olup olmadığının belirlenmesi için çoklu doğrusal regresyon analizi yapılmıştır. Araştırmanın sonucunda öğretmenlerin görüşlerine göre, görev yaptıkları okullarn örgütsel zekâ düzeylerinin yüksek düzeyde olduğu belirlenmiştir. Aynı zamanda öğretmenlerin yenilikçi çalışma davranışlarını yüksek düzeyde sergiledikleri tespit edilmiştir. Araştırmanın sonuçları, öğretmenlerin görev yaptıkları okulların örgütsel zekâ düzeyleri toplamı ve yenilikçi çalışma davranış düzeyleri toplamı arasında pozitif yönlü yüksek düzeyde anlaml bir ilişki bulunduğunu göstermektedir. Bu doğrultuda araştırma ile öğretmenlerin görev yaptıkları okulların örgütsel zekâ düzeyinin yenilikçi çalışma davranışın yüksek düzeyde etkilediğ $i$ sonucuna ulaşılmıştır.

Anahtar Kelimeler: Örgütsel Zeka, Yenilikçilik, Eğitimde Yenilikçilik, Yenilikçi Çalışma Davranışı.

\footnotetext{
${ }^{1}$ Bu çalışma, Belgin Tura tarafından Hacettepe Üniversitesi Eğitim Bilimleri Enstitüsü'nde Prof. Dr. Sait Akbaşlı danışmanlığında yürütülen "Örgütsel Zekâ Düzeyinin Öğretmenlerin Yenilikçi Çalışma Davranışları Üzerindeki Etkisi" başlıklı doktora tezinden üretilmiştir.
} 


\title{
The Impact of Organizational Intelligence Level on Teachers' Innovative Work Behavior
}

\begin{abstract}
This study was conducted to determine the impact of the organizational intelligence level of schools on teachers' innovative work behaviours. The study group of the study is 328 branch teachers working in public secondary schools and imam hatip secondary schools affiliated to the Ankara province Sincan District National Education Directorate in the 2020-2021 academic year, determined by the appropriate sampling method. Multidimensional Organizational Intelligence Scale and Innovative Work Behavior Scale were used in the study. Descriptive statistics were used in the analysis of the research data, and multiple linear regression analysis was used to determine whether the organizational intelligence level of the schools where teachers work was a significant predictor of teachers' innovative working behaviors. As a result of the study, according to the opinions of the teachers, it was determined that the organizational intelligence levels of the schools they work in are at a high level. In addition, it has been determined that teachers exhibit innovative work behaviors at a high level. The results of the study show that there is a highly significant positive correlation between the total organizational intelligence levels of the schools where teachers work and the total innovative work behavior levels. In this direction, it was concluded that the organizational intelligence level of the schools where teachers work has a high effect on innovative working behavior.
\end{abstract}

Key Words: Organizational Intelligence, Innovation, Innovation in Education, Innovative Work Behavior. 


\section{Giriş}

Günümüzde belirsizliğin, karmaşa ve kaosun eşiğinde, bilgi ve teknolojinin olanca hızı ile tüm toplumsal alanlarda hakimiyetini ortaya koyduğu ve teknolojik tekilliğe doğru bir yönelimin başladığı bir çağda, eğitim örgütlerinin de bu değişim ve dönüşüm dalgalarının dışında kalması beklenemez. Böylesi bir sorumluluk, eğitimi ve eğitim örgütlerini tüm boyutlarıyla yeniden değerlendirmeyi, değişen durumlara uyum sağlamada yeni stratejiler geliştirmeyi ve uygulamay1 zorunlu kılmaktadır. Dünyadaki pek çok eğitim sisteminin dijital çağın ve küreselleşmiş bir dünyanın taleplerini karşılamaya hazır olabilmesi için gereken reform ve dönüşümler, dünya çapındaki birçok ulusal hükümetin temel gündemini meydana getirmektedir. Ulusal hükümetlerin akıllı toplumlar yaratma temelinde şekillenen eğitim gündemi, dikkatleri eğitimsel yeniliklere ve zeki örgütler olması beklenen okul kurumuna yöneltmektedir.

Okul kurumu, gelişen toplumların sosyal düzeni sağlamak ve yaşamlarını bu düzen üzerinde sürdürebilmek amacıyla oluşturdukları, yeni neslin eğitim ihtiyacını karşılamakla sorumlu örgütlerdir. Ancak eğitim kurumunu sadece okul ile sınırlandırmak yanlış bir tutumdur (Akbaşlı ve Tura, 2019, s.1749). Eğitim, öncelikle ailede başlayan ve bireyin ait olduğu sosyal ve doğal çevre ile okul etkileşimi içerisinde yaşam boyu devam eden bir süreçtir (Akbaşli, 2007, s.10).

Eğitim çaba gerektiren bir uğraştır. Geçmişte eğitimcilerin ders kitabı ile sınırlı bilgi kümesini öğrencilere ezberletmekten ibaret olan bu uğraş, 21. yüzyılda bilgiye ulaşma yollarını öğrenme, ulaşılan bilgi yığını içerisinden ihtiyaç duyulan esas bilgiyi edinme, edinilen bilgiyi yaşamda problem çözme ve ürüne dönüştürme amaciyla kullanma becerilerini kazandırma şeklinde değişime uğramıştır. Yeni eğitim anlayışı, öğrencilere 21. yüzyılın becerilerinin kazandırılmasını gerekli kılarken, bu becerileri kazandırmakla sorumlu öğretmenlerin de aynı zamanda bu becerilere sahip olmasını zorunlu kılmaktadır.

Bir toplumun ve toplumu meydana getiren bireylerin niteliklerinin geliştirilmesinin temel mimarları, eğitim sistemlerinin temel unsuru olan öğretmenlerdir. Öğretmenlerin kalitesi öğretme-öğrenme uygulamalarında kendini göstermekte ve sadece bireylerin bilgisinin 
gelişmesinde değil, aynı zamanda özellikle eğitimlerinin ve kişiliklerinin oluşumunda doğrudan bir etkiye sahip olmaktadır. Bu nedenle, eğitimin başarısı, esas olarak eğitimin uygulayıcılarının, yani öğretmenlerin sahip oldukları becerilere bağlıdır (Akbaşlı , 2010, s.14).

Yeni çağın öğretmenleri, zihinlerini sadece öğretim programı ile sinırlandırmak yerine okulun dışındaki dünyayı, dünyada meydana gelen değişimleri ve okulun bu değişim sürecindeki rolünü fark ederek eğitim ve öğretim süreçlerini yenilikçi bir anlayışla ele almak ve bu süreçleri yenilikçi bir tarzda tasarlamak durumundadır. Yenilikçi çalışma davranışlarına sahip öğretmenler, öğrencilerinin özelliklerini ve birbirinden farklı ihtiyaçlarını yeni stratejiler kullanarak ele almakta, böylece öğrenme ve öğretim süreçlerinde öğrencilerinin yaratıcllıklarını geliştirmelerine yardımcı olmaktadır. Bu bağlamda yenilikçilik, öğretmenlik mesleğinin ötesinde okul örgütlerinin geliştirilmesi ve bilgi toplumuna dönüşüm sürecinde bir katalizör işlevi görmesi açısından hayati bir öneme sahiptir (Tura ve Akbaşlı, 2021, s.16).

Öğretmenlerin yenilik yeteneği, eğitim kurumlarında örgütsel yeniliğin merkezinde yer almaktadır. Yenilik yeteneği; yeni fikirleri, ürünleri veya süreçleri başarılı bir şekilde içselleştirme ya da uygulama becerisi, diğer bir ifadeyle örgütün yenilik ortaya koyma potansiyelidir. Yenilik yeteneği, örgütsel kaynak ve yeterliliklere bağlı olarak gelişmektedir. Yenilik yeteneği için en önemli kaynak ve yeterlilikler, örgütsel bilgi ve öğrenme ile ilgili becerilerdir. Öğretmenlerin yenilik yeteneğini çalışma davranışlarına yansıtarak yenilikçi eğitim ve öğretim süreçlerini gerçekleştirmesi beklenmektedir. Öğretmenlerin sahip olduğu kaynak ve yeterliliklerin işlenmesi, kullanılması ve yenilikçi çalışma davranışları ile ortaya konulması ise örgütsel zekaya bağlıdır. Yenilik, özünde zekayı içermektedir. Diğer bir ifadeyle bir yenilik aslında yeni bir fikir, bakış açısı ve uygulamalar bütünüdür (Van de Ven, 1986, s.591). Yenilikçi dehanın yaratıcı kıvılcımı ya da yeniliği tanıyan ve destekleyen örgütsel sistemlerin zekası olmadığında, sorunlara yeni ve yararlı çözümler bulmak da güçleşmektedir. Günümüzün en başarılı girişimleri, zeki girişimler olarak dikkati çekmektedir (Glynn, 1996, s.1081). Okul örgütlerinde örgüt zekasının geliştirilmesi, bilgi, öğrenmeyle ilgili kaynakların ve yetkinliklerin kullanımını artırarak öğretmenlerin yenilik yeteneğinin geliştirilmesini ve yenilikçi çalı̧̧ma 
davranışları ile gösterilmesini desteklemektedir (Kalkan, 2005, s.48-49). Örgütsel zeka ve yenilikçi çalışma davranışlarına ilişkin kavramsal açıklamalara aşağıda yer verilmiştir.

\section{Örgütsel Zeka}

Zekâ kavramı öncelikle bireysel olarak ele alınmakla birlikte kimi yazarlar tarafından kolektif bir kapsamda değerlendirme ve ölçmeye tabi tutulmuştur (Glynn, 1996, s.1087). Örgütlerde zekâ kavramı ilk kez 1967 yılında Amerikalı bir profesör olan Harold Wilensky tarafından ortaya atılmıştır. Wilensky (1967; akt. Azma, Mostafapour ve Rezaei, 2012, s. 95), örgütlerde toplanan zekaya ilişkin bilgilerin doğru örgütü belirlemek için kullanılabileceğini ifade ederek zekanın örgütün verimliliği ve etkinliği üzerinde büyük bir etkiye sahip olduğunu ve örgütsel kararlara yardımcı olması için kurumsal bilginin özelliklerinin ve ölçümünün düşünülebileceğini ileri sürmüştür.

Allee (1997, s.42), bir sistem olarak örgütlerin karmaşık yapılara sahip değişken bir çevrede varlığını sürdürebilmesi için paylaşılan sosyal süreçlerde bilgi üretmesi ve kullanması gerektiğini ileri sürmüş ve bu nedenle bireysel düzeyin ötesinde topluluk düzeyinde bir zekaya ihtiyaç olduğunu ifade etmiştir. Senge (2007), örgütlerde bireylerin grup halinde öğrenebileceğini ve bunu gerçekleştiren takımların eşgüdümlü eylem için kapasite oluşturarak bireysel zekâ seviyesini aşan kolektif bir zekâ seviyesine erişebileceklerini vurgulamıştır.

Örgütsel zekaya ilişkin olarak alanyazın incelendiğinde; grup zekâsı, kolektif zekâ, yarışmacı zekâ gibi kavramlara rastlanmaktadır. Bu kavramlar, bazen örgütsel zekâ anlamında kullanılabilmektedir. Bununla birlikte, grup zekasına atfedilen anlamların örgütsel zekayı içermediği, kolektif zekaya atfedilen anlamların çoğu kez örgütsel zekadan çok daha kapsayıcı olduğu, yarışmacı zekanın ise örgütsel varoluşa sadece diğer örgütlerle rekabet şeklinde bir tutumu ortaya koyduğunu söylemek mümkündür (Erçetin, 2004, s.41).

Zekâ kavramının örgütlere uyarlanmasının temelinde bazı varsayımlar bulunmaktadır. İlk varsayım, insan ve örgütsel zekâ arasındaki fonksiyonel benzerliktir. Örgütsel zekâ, bir örgütün bilgiyi amaca yönelik bir şekilde işleme, yorumlama, kodlama, kullanma ve 
bunlara erişme yeteneğidir. Bu şekilde örgüt, faaliyet gösterdiği çevrede uyarlanabilme potansiyelini artırabilmektedir. Bu tanım ikinci varsayımı ortaya koymaktadır, yani örgütsel zekâ uyarlanabilirdir. Bireysel zekâ gibi örgütsel zekâ da problemlerin çözülmesi, amaçların karşılanması ve çevresel zorluklara etkili yanıtlar verilmesi ile ilgilidir. Üçüncü varsayım ise örgütsel zekanın örgütsel başarıları ve başarısızlıkları vurgulayan deneysel bir öğrenme süreci olmasıdır (Glynn et al., 1994'den akt. Glynn, 1996, s.1088). Glynn (1996, s.1088), örgütsel zekanın fonksiyonel olarak bireysel zekâ ile benzerlikler taşımasına rağmen açıkça bireysel zekâ ile aynı olmadığını ifade ederek, örgütsel zekayı kolektif davranışın bir özelliği olarak değerlendirmiş ve sosyal bir çıktı olduğunu ileri sürmüştür.

Veryard (2018, s.1), bu doğrultuda örgütsel zekânın kolektif beceriler olarak kabul edilen karmaşık durumları anlamlandırma ve etkili bir şekilde hareket etme, çevredeki olayları ve işaretleri yorumlama ve bunlara göre hareket etme, amaca uygun bilgiyi üretme, kullanma, paylaşımda bulunma ve tecrübelerinden öğrenme ve yansıtma becerileri ile karakterize edilebileceğini belirtmiştir. Liebowitz (2000)'e göre örgütsel zekayı, örgüt içerisinde paylaşılan vizyon, yenileme süreçleri ve yön belirlemeye katkı sağlayan tüm zekaların bir kolektif birleşimi olarak ifade ederken; Albrecht (2003, s.15), örgütsel zekâyı bir organizasyonda var olan zihin gücünün tamamın faaliyete geçirme ve bu zihin gücünü örgütün misyonunu gerçekleştirmek için odaklama yeteneği olarak tanımlamıştır. Erçetin (2001, s.58) ise örgütsel zekâ kavramını örgütün varlığını sürdürebilmesini olanaklı kılan yeteneklerin bütünü ve bu yeteneklerin kullanılması şeklinde açıklamıştır. Bu yetenekler; eylem ve tepkide çabukluk, değişen durumlara uyum sağlayabilme, işleyişte esnek ve rahat olabilme, sezebilme ve öngörülü olabilme, açı fikirli olabilme, hayal gücünü kullanabilme ve yenilenebilmedir.

\section{Yenilikçi Çalışma Davranışı}

Yenilikçi çalışma davranışı, alanyazında ilk olarak West ve Farr (1989'dan akt. Janssen, 2000, s. 288) tarafından rol performansına, gruba veya örgüte katkı sunmak için iş rolü, grup veya örgüt içerisinde yeni 
fikirlerin ortaya çıkarılması, tanıtılması ve uygulanması olarak tanımlanmıştır. Farr ve Ford (1990) yenilikçi çalışma davranışını yeni ve faydalı fikirlerin, süreçlerin, ürünlerin ya da yöntemlerin çalışanın iş rolüne bilinçli bir şekilde dahil edilmesi olarak tanımlarken; Janssen (2000, s.288) ise yenilikçi çalışma davranışını, çalışanların iş sürecinde rol performansına, gruba ya da örgüte yarar sağlamak amacıyla yeni fikirleri üretmesi, tanıtması ve sonuçta uygulanabilecek bir yenilik prototipi ya da modeli geliştirerek fikri gerçekleştirmesi olarak ifade etmiştir.

Bos-Nehles, Bondarouk ve Nijenhuis (2017, s.382), örgütsel etkinliği ve başarıyı artırmak amacıyla ürünler, teknolojiler, prosedürler ya da iş süreçleri ile ilgili yeni fikirlerin üretilmesi, işlenmesi ve uygulanmasına yönelik olarak gerçekleştirilen tüm bireysel eylemlerin yenilikçi çalışma davranışı olduğunu belirtmiştir. Yenilikçi çalışma davranışlarına örnek olarak, çalışanların yeni teknolojileri araştıran, hedeflere ulaşmak için yeni stratejiler geliştiren, yeni çalışma yöntemleri uygulayan ve yenilik fikirlerini destekleyen ve bu fikirleri uygulamak için kaynaklar sağlayan davranışlarını göstermek mümkündür (Kheng, Mahmood ve Beris, 2013, s.93).

Yenilikçi çalışma davranışı, gönüllü ve isteğe bağlı bir çalışan davranışı, iş rollerinin gerekliliğinin ötesine geçen bir davranıştır (Sanders, Moorkamp, Torka, Groeneveld ve Groeneveld, 2010, s.60). Ancak yenilikçi çalışma davranışı, çalışanların işlerini yerine getirirken rol gerekliliklerinin ötesine geçme derecesi olan ekstra rol davranışı (Blader ve Tyler, 2009, s.445) ile aynı anlama gelmemektedir. Benzer şekilde, Abstein, Heidenreich ve Spieth (2014, s.94) bunu gönüllü ve isteğe bağlı bir davranış olarak tanımlamaktadır, çünkü her çalışan diğerlerinin yanı sıra gösterdiği seviyeye karar verme yeteneğine sahiptir.

Scott ve Bruce (1994), yenilikçi çalışma davranışını üç aşamadan oluşan bir süreç şeklinde ifade etmektedir. Yenilikçi çalışma davranışının ilk aşamasında mevcut problem tanımlanarak soruna yönelik yeni fikir veya çözümler üretilmektedir. Bir sonraki aşamada yenilikçi birey, geliştirdiği fikir için destek arayışına girmekte ve fikri destekleyenlerden meydana gelen bir grup oluşturmaya çalışmaktadır. Son aşamada yenilikçi birey, yenilik fikrini bir model veya prototip haline 
getirmektedir. Bundan dolayı yenilikçi çalışma davranışı, her aşamasında farklı etkinlik ve davranışları kapsayan bir süreç olarak değerlendirilmektedir. Messmann ve Mulder (2011), yenilikçi çalışma davranışının, yenilikçi fikirleri dinlemeyi, değerlendirmeyi, kabul etmeyi, eylem stratejisi oluşturmayı ve bu fikirler için destekçiler bulmayı içerdiğini belirtmiştir. Yenilikçi çalışma davranışı gösteren öğretmenler, mesleki gelişimlerini sürdürebilmekte, çalışma ortamlarını iyileştirebilmekte, performansını artırabilmekte ve meslektaşları ya da okulun dışındaki diğer paydaşlar tarafından önerilen iyileştirmeleri benimsemeye istekli olabilmektedirler (Bos-Nehles, Bondarouk ve Nijenhuis, 2017, s.382). Yeniliklerin köşe taşı olarak değerlendirilen yenilikçi çalışma davranışları, örgütler ve çalışanlar için hayati bir önem taşımaktadır. Dinamik ortamlarda gelişen yenilikçi davranışlar, örgütsel süreçlerin etkinliği ve örgütün başarısı ayrıca ortaya çıkan problemlerin çözümü için yardımcı olarak örgütsel rekabet üstünlüğü sağlamaktadır (Çevik Tekin, 2019, s. 36).

\section{Araştırmanın Amacı ve Önemi}

Okulların örgütsel zekâ düzeylerinin öğretmenlerin çalışma davranışları üzerindeki etkisinin belirlenmesi, okulların potansiyellerinin keşfi, kurumsal kapasitelerinin artırılması ve bu kapasitenin en değerli unsuru olan öğretmenlerin geliştirilmesi açısından stratejik bir öneme sahiptir. $\mathrm{Bu}$ araştırmayla, okulların örgütsel zeka düzeylerinin eğitim ve öğretimin ana uygulayıcıları olan öğretmenlerin yenilikçi çalışma davranışları üzerindeki etkisinin ortaya çıkarılması sağlanarak, 21. yüzyılın eğitim sisteminin temellerini kurmakla yükümlü politika yapıcılarına ve eğitimcilere fikir vermesi umulmaktadır.

Yukarıda yapılan açıklamalar doğrultusunda bu araştırmanın amacı, okulların örgütsel zekâ düzeyinin öğretmenlerin yenilikçi çalışma davranışları üzerindeki etkisinin belirlenmesidir. Araştırmada aşağıdaki sorulara yanit aranmiştır.

1. Öğretmenlere göre, öğretmenlerin görev yaptıkları okulların örgütsel zekâ düzeyi nedir?

2. Öğretmenlere göre, öğretmenlerin yenilikçi çalışma davranışları nasıldır? 
3. Öğretmenlere göre, öğretmenlerin görev yaptıkları okulların örgütsel zekâ düzeyi, öğretmenlerin yenilikçi çalışma davranışlarının anlamlı bir yordayıcısı mıdır?

\section{Yöntem}

Araştırma, tarama modelinde gerçekleştirilen korelasyonel bir çalışmadır. Neuman'a (2016) göre, taramalar, insanların inançlarını, düşüncelerini, sahip oldukları özelliklerini ve şimdiki veya geçmişteki davranışlarını ortaya çıkarmaya çalışır. Bundan dolayı taramalar, bireylerin ifade ettikleri inançları ya da davranışlarını içeren araştırma soruları için uygun görülmektedir. Korelasyonel araştırmalar ise iki veya daha fazla değişken arasındaki ilişkileri belirlemek ve neden-sonuç ile ilgili ip uçlarına ulaşmak amacıyla yapılmaktadır. Korelasyonel araştırmalar, araştırmanın değişkenleri arasındaki ilişkinin türü ya da türlerinin ne dereceye kadar var olduğunu bulmaya çalışmaktadır (Büyüköztürk, Kılıç Çakmak, Akgün, Karadeniz ve Demirel, 2019, s.16). Araştırma kapsamında ele alınan öğretmenlerin görüşlerine göre, görev yaptıkları okulların örgütsel zekâ düzeyinin öğretmenlerin yenilikçi çalışma davranışları üzerindeki etkisinin belirlenmesi açısından bu araştırma, tarama modelinde bir korelasyonel araştırmaya uygundur.

\section{Çalışma Grubu}

Araştırmanın çalışma grubunu, seçkisiz olmayan örnekleme yöntemleri içerisinde yer alan uygun örneklem yöntemi ile tespit edilen, 2020-2021 eğitim öğretim yılında Ankara ili Sincan İlçe Milli Eğitim Müdürlüğü’ne bağlı kamu ortaokulu ve imam hatip ortaokullarında görevli 328 branş öğretmeni oluşturmaktadır.

\section{Veri Toplama Araçları}

Araştırmada, “Çok Boyutlu Örgütsel Zekâ Ölçeği" ve "Innovative Work Behaviour (IWB)" Yenilikçi Çalışma Davranışı Ölçeği" veri toplama aracı olarak kullanılmıştır. 
Çok Boyutlu Örgütsel Zekâ Ölçeği: Öğretmenlerin algıları doğrultusunda görev yaptıkları okulların örgütsel zekâ düzeyini belirlemek amacıyla, Erçetin, Potas ve Açıkalın tarafından önceki araştırmalarında geliştirilmiş (2001，2004，2007, 2009, 2010) ve 2015 yılında Erçetin, Potas ve Açıkalın tarafından ise yeniden düzenlemesi yapılmıştır. Erçetin, Potas ve Koç (2016) tarafından ise ölçek, iş organizasyonları için uygulanmıştır. "Çok Boyutlu Örgütsel Zekâ Ölçeği", yedi boyut ve toplam 67 maddeden meydana gelmiştir. Ölçeğin güvenirliğine ilişkin olarak, Potas, Erçetin ve Koçak (2010) tarafından Cronbach alfa güvenirlik katsayısı, ölçeğin bütünü için .99 olarak tespit edilmiştir. Ölçeğin boyutlarına ilişkin Cronbach alfa güvenirlik katsayıları Tablo 1'de yer almaktadır. Ölçeğin güvenirliğine ilişkin olarak hesaplanan Cronbach alfa güvenirlik katsayılarının yüksek düzeyde olduğu görülmektedir.

Tablo 1. Çok Boyutlu Örgütsel Zekâ Ölçeğine İlişkin Cronbach Alfa Güvenirlik Katsayılar

\begin{tabular}{ll}
\hline Boyutlar & $\alpha$ Katsayısı \\
\hline Değişen Durumlara Uyum Sağlama I & .91 \\
Paydaşlarla Etkili İletişim & .95 \\
Eylemde ve Tepkide Çabukluk & .93 \\
Sezebilme ve Öngörebilme & .96 \\
Hayal Gücünü Kullanabilme ve Yaratıcıllk & .93 \\
İşleyişte Esnek ve Rahat Olabilme & .91 \\
Değişen Durumlara Uyum Sağlama II & .95 \\
Tüm Boyutlar & .99 \\
\hline
\end{tabular}

Kaynak: Potas, N., Erçetin, Ş. Ş., Koçak, S. (2010). Multi Dimensional Organizational Intelligence Measurements for Determining the Institutional and Managerial Capacity of Girl's Technical Education Institution (Diyarbakır, Şanluurfa, Konya/Turkey). African Journal of Business Management, 4(8), 1644-1651.

Innovative Work Behaviour Scale (IWB) - Yenilikçi Çalışma Davranışı Ölçeği (YÇD): Dorenbosch, Engen ve Verhagen (2005) tarafından geliştirilmiş ve bu araştırmanın yazarları tarafından Türkçe'ye uyarlanmıştır. Yenilikçi Çalışma Davranışı Ölçeği, dört boyut ve 21 maddeden meydana gelmiştir. Ölçeğin boyutları ve her bir boyuta ait madde sayıları Tablo 3'te yer almaktadır. 
Tablo 2. Yenilikçi Çalışma Davranışı Ölçeği Boyutları ve Madde Sayıları

\begin{tabular}{ll}
\hline Boyutlar & Madde Sayısı \\
\hline Yaratıcılık Odaklı Çalışma Davranışı & 10 \\
Uygulama Odaklı Çalışma Davranışı & 6 \\
Bilgisayar Teknolojisinin Kullanımına Yönelik Yenilikçi Davranış & 3 \\
Finansal Kaynakların Kullanımına Yönelik Yenilikçi Davranış & 2 \\
Tüm Boyutlar & 21 \\
\hline
\end{tabular}

Dorenbosch, L., Engen, M. and Verhagen, M. (2005). On-The-Job Innovation: The Impact of Job Design and Human Resource Management through Production Ownership. Creativity and Innovation Management, 14(2), 129-141.

Dorenbosch, Engen ve Verhagen (2005), gerçekleştirdikleri faktör analizi sonucunda dört boyutlu olarak geliştirdikleri ölçeğe ilişkin olarak araştırmalarında veri topladıkları çalışma grubunun niteliğinden dolayı (büyük bir Hollanda yerel yönetim kuruluşunun yönetici olmayan 450 personeli) iki boyutu değerlendirmeye almış ve Cronbach alfa güvenirlik katsayılarını "Yaratıcılık Odaklı Çalışma Davranışı" boyutu için .90 ve "Uygulama Odaklı Çalışma Davranışı" boyutu için .88 olarak hesaplamıştır. İki boyutun toplam Cronbach alfa güvenirlik katsayısı ise .92 olarak hesaplanmıştır.

Türkçeye uyarlama sürecinde ölçeğin "Finansal Kaynakların Kullanımına Yönelik Yenilikçi Davranış" boyutu kamu okullarında öğretmenlerin görev yaptıkları okulların finansal edinim ve yönetiminde karar yetkisinin bulunmaması nedeniyle kapsam dışı bırakılmış ve ölçek üç boyut ve on dokuz madde olarak Türk diline uyarlanmıştır. Uyarlama ölçeğin Cronbach Alpha Katsayısı ise yaratıcılık odaklı çalışma davranışı boyutu için .966, uygulama odaklı çalışma davranışı boyutu için 942 ve bilgisayar teknolojisinin kullanımına yönelik yenilikçi davranış boyutu için 951 olarak hesaplanmıştır. Ölçeğin genel güvenirlik katsayısı ise bu üç alt boyutun güvenirlik değerlerinin ortalaması alınarak .953 olarak bulunmuştur.

\section{Verilerin Analizi}

Araştırma verileri hem yüz yüze hem de çevrim-içi veri toplama aracı kullanılarak toplanmıştır. Araştırma kapsamında "Çok Boyutlu Örgütsel Zekâ Ölçeği" ve "Yenilikçi Çalışma Davranışı Ölçeği" birlikte uygulanarak örneklemi oluşturan öğretmenlerin görüssleri veriye 
dönüştürülmüş̧ür. Araştırma verilerinin analizinde betimsel istatistikler ile öğretmenlerin görev yaptıkları okulların örgütsel zekâ düzeyinin öğretmenlerin yenilikçi çalışma davranışlarının anlamlı bir yordayıcısı olup olmadığının belirlenmesi için ise çoklu doğrusal regresyon analizi yapılmıştır. Verilerin analizi hazır istatistik paket programı aracılığıyla gerçekleştirilmiştir.

\section{Bulgular}

Araştırmanın birinci alt problemi, öğretmenlerin görüşlerine göre, öğretmenlerin görev yaptıkları okulların örgütsel zekâ düzeyinin belirlenmesidir. $\mathrm{Bu}$ amaçla uygulanan betimsel istatistiklere dair sonuçlar Tablo 3'te görülmektedir.

Tablo 3. Öğretmenlerin Görüşlerine Göre Okullarn Örgütsel Zekâ Düzeylerine Ait Betimsel İstatistikler $(\mathrm{N}=328)$

\begin{tabular}{|c|c|c|c|c|c|c|}
\hline \multicolumn{2}{|l|}{ Değişken } & $\overline{\boldsymbol{X}}$ & S.S. & Medyan & Min & Max \\
\hline \multicolumn{2}{|l|}{ Örgütsel Zekâ Düzeyi } & 3.87 & 0.83 & 4.01 & 1.46 & 4.97 \\
\hline $\begin{array}{l}1 . \\
\text { Sağlama I }\end{array}$ & Değişen Durumlara Uyum & 3.80 & 0.77 & 4.00 & 1.33 & 5.00 \\
\hline 2. & Paydaşlarla Etkili İletişim & 4.01 & 0.81 & 4.17 & 1.08 & 5.00 \\
\hline 3. & Eylem ve Tepkide Çabukluk & 4.04 & 0.76 & 4.20 & 1.20 & 5.00 \\
\hline 4. & Sezebilme ve Öngörebilme & 3.93 & 0.89 & 4.00 & 1.10 & 5.00 \\
\hline $\begin{array}{l}5 . \\
\text { ve Yaratıc1 }\end{array}$ & $\begin{array}{l}\text { Hayal Gücünü Kullanabilme } \\
\text { llık }\end{array}$ & 3.75 & 0.95 & 3.88 & 1.00 & 5.00 \\
\hline $\begin{array}{l}6 . \\
\text { Olabilme }\end{array}$ & İşleyişte Esnek ve Rahat & 3.71 & 1.01 & 4.00 & 1.00 & 5.00 \\
\hline $\begin{array}{l}7 . \\
\text { Sağlama II }\end{array}$ & Değişen Durumlara Uyum & 3.82 & 0.93 & 4.02 & 1.05 & 5.00 \\
\hline
\end{tabular}

Tablo 3 incelendiğinde, öğretmenlerin görüşlerine göre, görev yaptıkları okulların örgütsel zekâ düzeyine ilişkin ortalama değerin $\bar{X}=$ 3.87 olduğu görülmektedir. Bu bulguya dayanarak, öğretmenlerin görüşlerine göre, görev yaptıkları okulların örgütsel zekâ düzeylerinin yüksek düzeyde olduğu söylenebilir. Çok Boyutlu Örgütsel Zekâ Ölçeği, alt boyutları açısından değerlendirildiğinde, diğer tüm alt boyutlarında yüksek düzeyde olduğu görülmektedir. Ölçeğin alt boyutlarında en yüksek ortalama, eylem ve tepkide çabukluk boyutunda $(\bar{X}=4.04)$ ve en düşük ortalama ise işleyişte esnek ve rahat olabilme boyutunda $(\bar{X}=3.71)$ gerçekleşmiştir. Bu doğrultuda eylem ve tepkide çabukluk boyutunda 
öğretmenlerin, görev yaptıkları okullarda, kararların hızlı bir şekilde alınarak uygulanması ve okulu etkileyen her türlü duruma, uygun ve doğru tepkilerin verilerek eylem geliştirilebilmesi gibi becerilerin diğer becerilere oranla daha fazla gerçekleştiğini düşündükleri ifade edilebilir. Bununla birlikte öğretmenlerin, işleyişte esnek ve rahat olabilme boyutunda görev yaptıkları okulların işleyişine yönelik kuralların değişebilir nitelikte olması, bürokratik iş ve işlemlerin okulun hızını azaltmayacak düzeyde yapılması ve çalışanların her konuda tercih yapabilme özgürlüğüne sahip olmaları gibi becerilerin diğer becerilere oranla daha az ortaya çıktığını düşündükleri söylenebilir.

Araştırmanın ikinci alt problemi, öğretmenlerin görüşlerine göre, öğretmenlerin yenilikçi çalışma davranışlarının düzeyinin belirlenmesidir. Bu amaçla uygulanan betimsel istatistiklerin sonuçları Tablo 4'te görülmektedir.

Tablo 4. Öğretmenlerin Yenilikçi Çalışma Davranışlarına Ait Betimsel İstatistikler $(N=328)$

\begin{tabular}{lccccc}
\hline Değişken & $\overline{\boldsymbol{X}}$ & S.S. & Medyan & Min & Max \\
\hline Yenilikçi Çalışma Davranışı Düzeyi & 3.98 & 0.86 & 4.16 & 1.05 & 5.00 \\
Yaratıcılık Odaklı Çalışma Davranışı & 4.00 & 0.90 & 4.20 & 1.10 & 5.00 \\
Uygulama Odaklı Çalışma Davranışı & 3.87 & 0.88 & 4.00 & 1.00 & 5.00 \\
Bilgisayar Teknolojisinin Kullanımına & 4.15 & 0.98 & 4.33 & 1.00 & 5.00 \\
Yönelik Yenilikçi Davranış & & & &
\end{tabular}

Tablo 4 incelendiğinde, öğretmenlerin yenilikçi çalışma davranışlarına ilişkin ortalama değer $\bar{X}=3.98$ olarak bulunmuştur. Diğer bir ifade ile öğretmenlerin yenilikçi çalışma davranışlarını yüksek düzeyde gösterdiklerini söylemek mümkündür. Diğer taraftan, ölçeğin alt boyutlarına ait en yüksek ortalamanın, bilgisayar teknolojisinin kullanımına yönelik yenilikçi davranış $(\bar{X}=4.15)$ ve en düşük ortalamanın ise uygulama odaklı çalışma davranışı $(\bar{X}=3.87)$ boyutlarında gerçekleştiği görülmektedir. $\mathrm{Bu}$ doğrultuda, öğretmenlerin yeni bilgisayar teknoloji ve uygulamalarını araştırma, öğrenme ve çalışmalarında etkili bir şekilde kullanma becerilerini diğer becerilerine oranla daha fazla sergileyebildiklerini düşündükleri ifade edilebilir. Bununla birlikte öğretmenlerin, yeni fikir ve çözümlerini, yönetici ve meslektaşlarını ikna ederek ve desteklerini alarak uygulamaya geçirme 
becerilerini ise diğer becerilerine oranla daha az sergileyebildiklerini düşündüklerini söylemek mümkündür.

Araştırmanın üçüncü alt problemi, öğretmen görüşlerine göre, örgütsel zekâ düzeyinin öğretmenlerin yenilikçi çalışma davranışlarını yordayıp yordamadığının belirlenmesidir. Bu amaçla yenilikçi çalışma davranış düzeyinin bağımlı değişken olarak ele alındığı çoklu doğrusal regresyon analizi yapılmıştır. Bu kapsamda, öncelikle çoklu doğrusal regresyon analizinin varsayımları test edilmiştir. Buna göre, öncelikle bağımsız değişkenlerle bağımsız değişken arasında doğrusal bir ilişkinin var olup olmadığı kontrol edilmiştir. Standardize edilmiş artık değerler ile standardize edilmiş yordanan değerler açısından doğrusal bir ilişkinin olduğu, hataların normale yakın bir dağılım gösterdiği ve eş varyanslılık varsayımının sağlandığı söylenebilir. Ayrıca bağımsız değişkenler arasında çoklu bağlantı sorununun olup olmadığı belirlemek için varyans şişme faktörleri (VIF) ve Tolerance değerleri incelenmiştir. VIF değerinin $10^{\prime}$ dan düşük ve Tolerance değerinin ise 0.1 'in üzerinde olması değişkenler arası çoklu bağlantı probleminin olmadığına işaret etmektedir (Çokluk, Şekercioğlu ve Büyüköztürk, 2016; Mertler ve Vannatta Reinhart, 2017). Bu doğrultuda bağımsız değişkenlere yönelik olarak gerçekleştirilen analiz sonucunda, VIF değerinin tek bir değişken hariç 10'dan düşük biçimde 3.081 ile 9.796 arasında değiştiği görülmüştür. Değişen durumlara uyum sağlama II alt boyutuna ait VIF değeri 11.812 olduğu için ortalamaya merkezleme (mean centering) işlemi yapılmıştır. Tolerance değerleri ise 0.085 ile 0.325 arasında değişmektedir. Verilerin tümü birlikte ele alındığında bağımsız değişkenler arasında çoklu bağlantı probleminin olmadığı söylenebilir. Çoklu doğrusal regresyon analizinin varsayımlarının incelenmesinin ardından yenilikçi çalışma davranışının bağımlı değişken olduğu model analiz edilmiştir. Bu çerçevede, yenilik çalışma davranışlarının yordanmasına ilişkin çoklu regresyon analizi sonuçları Tablo 5'te gösterilmiştir. 
Tablo 5. Yenilikçi Çalışma Davranışlarının Yordanmasına İlişkin Çoklu Regresyon Analizi

\begin{tabular}{|c|c|c|c|c|c|c|c|}
\hline Değişken & B & Standart Hata & $\beta$ & $t$ & $\mathrm{p}$ & İkili $\mathbf{r}$ & Kismi r \\
\hline Sabit & 2.042 & .379 & & 5.386 & .000 & & \\
\hline $\begin{array}{l}\text { Değişen Durumlara } \\
\text { Uyum Sağlama I }\end{array}$ & .333 & .059 & .297 & 5.641 & .000 & .747 & .301 \\
\hline $\begin{array}{l}\text { Paydaşlarla Etkili } \\
\text { İletişim }\end{array}$ & .346 & .081 & .325 & 4.244 & .000 & .801 & .231 \\
\hline $\begin{array}{l}\text { Eylem ve Tepkide } \\
\text { Çabukluk }\end{array}$ & -.145 & .067 & -.128 & -2.154 & .032 & .667 & -.120 \\
\hline $\begin{array}{l}\text { Sezebilme ve } \\
\text { Öngörebilme } \\
\text { Hayal Gücünü }\end{array}$ & .029 & .085 & .030 & .340 & .734 & .756 & .019 \\
\hline $\begin{array}{l}\text { Kullanabilme ve } \\
\text { Yaratıcılık }\end{array}$ & -.002 & .081 & -.002 & -.021 & .984 & .750 & -.001 \\
\hline $\begin{array}{l}\text { İşleyişte Esnek ve } \\
\text { Rahat Olabilme }\end{array}$ & -.064 & .080 & -.075 & -.801 & .424 & .748 & -.045 \\
\hline $\begin{array}{l}\text { Değişen Durumlara } \\
\text { Uyum Sağlama II }\end{array}$ & .410 & .095 & .443 & 4.295 & .000 & .787 & .233 \\
\hline
\end{tabular}

$R=0.843, R^{2}=0.705, F(7.320)=112.551, p=.000$

Tablo 5'te yer alan bağımsız değişkenlerle bağımlı değişken arasındaki ikili ve kısmi ilişkiler incelendiğinde, yenilikçi çalışma davranışları ile örgütsel zeka düzeyinin değişen durumlara uyum sağlama I boyutu arasında pozitif ve yüksek düzeyde bir ilişkinin olduğu ( $\mathrm{r}=.747)$ ancak diğer değişkenler kontrol edildiğinde ise iki değişken arasındaki ilişkinin $\mathrm{r}=.301$ olarak gerçekleşmiştir. Öğretmenlerin yenilikçi çalışma düzeyi ile öğretmenlerin örgütsel zeka düzeyinin paydaşlarla etkili iletişim boyutu arasında pozitif ve yüksek düzeyde bir ilişkinin olduğu ( $r=.801)$ izlenmektedir. Diğer taraftan, diğer değişkenler kontrol edildiğinde ise iki değişken arasındaki ilişki $r=.231$ olarak belirlenmiştir. Öğretmenlerin yenilikçi çalışma düzeyi ile öğretmenlerin örgütsel zeka düzeyinin eylem ve tepkide çabukluk boyutu arasında pozitif ve yüksek düzeyde bir ilişkinin olduğu $(r=.667$ görülmektedir. Ancak, diğer değişkenler kontrol edildiğinde ise iki değişken arasındaki ilişki r=-.120 olarak tespit edilmiştir.

Öğretmenlerin yenilikçi çalışma düzeyi ile öğretmenlerin örgütsel zeka düzeyinin sezebilme ve öngörebilme boyutu arasında pozitif ve yüksek düzeyde bir ilişkinin olduğu $(r=.756)$ görülmektedir. Ancak, diğer değişkenler kontrol edildiğinde ise iki değişken arasındaki ilişki $\mathrm{r}=.019$ olarak belirlenmiştir. Öğretmenlerin yenilikçi çalışma düzeyi ile öğretmenlerin örgütsel zeka düzeyinin hayal gücünü kullanabilme ve 
yaratıcılık boyutu arasında pozitif ve yüksek düzeyde bir ilişkinin olduğu ( $\mathrm{r}=.750)$ izlenmektedir. Buna karşın, diğer değişkenler kontrol edildiğinde ise iki değişken arasındaki ilişki $r=-.001$ şeklinde hesaplanmıştır. Öğretmenlerin yenilikçi çalışma düzeyi ile öğretmenlerin örgütsel zeka düzeyinin işleyişte esnek ve rahat olabilme boyutu arasında pozitif ve yüksek düzeyde bir ilişkinin olduğu ( $\mathrm{r}=.748)$ görülmektedir. Buna karşın, diğer değişkenler kontrol edildiğinde ise iki değişken arasındaki ilişki r=-.045 şeklinde hesaplanmıştır. Öğretmenlerin yenilikçi çalışma düzeyi ile öğretmenlerin örgütsel zeka düzeyinin değişen durumlara uyum sağlama II boyutu arasında pozitif ve yüksek düzeyde bir ilişkinin olduğu ( $\mathrm{r}=.748)$ görülmektedir. Buna karşın, diğer değişkenler kontrol edildiğinde ise iki değişken arasındaki ilişki $r=.233$ olarak tespit edilmiştir.

Öğretmenlerin örgütsel zeka düzeyi alt boyutları ve yenilikçi çalışma davranışı ile yüksek düzeyde ve anlamlı bir ilişki göstermektedir $\left(\mathrm{R}=.843, \mathrm{R}^{2}=.705, \mathrm{p}<.01\right)$. Bu doğrultuda, öğretmenlerin örgütsel zeka düzeyi yenilikçi çalışma davranışına ilişkin toplam varyansın yaklaşık \%71'ini açıklamaktadır. Standardize edilmiş regresyon katsayısına $(\beta)$ göre bağımsız değişkenlerin yenilikçi çalışma düzeyi üzerindeki önem derecesi sırasıyla, değişen durumlara uyum sağlama II, paydaşlarla etkili iletişim, değişen durumlara uyum sağlama I, eylem ve tepkide çabukluk, işleyişte esnek ve rahat olabilme, sezebilme ve öngörebilme, hayal gücünü kullanabilme ve yaratıcllık biçiminde gerçekleşmiştir. Regresyon katsayılarının anlamlılığına ilişkin t-testi sonuçları incelendiğinde, değişen durumlara uyum sağlama I, eylem ve tepkide çabukluk, işleyişte esnek ve rahat olabilme, sezebilme ve öngörebilme boyutlarının anlamlı bir yordayıcı olmadığı görülmektedir. Bu kapsamda, bu boyutların yenilikçi çalışma davranışlarının yordanmasında önemli bir etkiye sahip olmadığını ifade etmek mümkündür.

\section{Tartışma ve Sonuç}

Araştırma, örgütsel zekâ düzeyinin öğretmenlerin yenilikçi çalışma davranışları üzerindeki etkisinin belirlenmesi amacıyla 2020-2021 eğitim öğretim yılında Ankara ili Sincan ilçesi kamu ortaokul ve imam hatip 
okullarında, gerçekleştirilmiştir. Bu amaç çerçevesinde araştırmadan elde edilen sonuçlar aşağıda sunulmuştur.

Araştırmada, öğretmenlerin görüşlerine göre, görev yaptıkları okulların örgütsel zekâ düzeylerinin yüksek düzeyde olduğu sonucuna ulaşılmıştır. Benzer şekilde İmamoğlu Akman ve Akman (2019) ile Turan (2017), araştırma bulguları ile tutarlı olarak okulların örgütsel zekâ düzeyini yüksek, Neyişci (2015) ise çok yüksek düzeyde bulgulamıştır. Diğer taraftan Erçetin, Potas, Hamedoğlu ve Kısa (2011), Neyişci, Potas ve Erçetin (2018) ile Potas, Erçetin ve Koçak (2010) araştırmalarında okulların örgütsel zekâ düzeyini orta olarak tespit etmiştir. Aynı şekilde Potas, Erçetin ve Bayrakçeken (2009), bir yükseköğretim kurumunda gerçekleştirdiği araştırmasında örgütsel zekâ düzeyini orta olarak bulgulamıştır. Araştırmada ayrıca okulların örgütsel zekâ düzeylerine yönelik tüm alt boyutların tamamını yüksek düzeyde olduğu belirlenmiştir. Alt boyutlar açısından en yüksek ortalama, eylem ve tepkide çabukluk boyutunda ve en düşük ortalama ise işleyişte esnek ve rahat olabilme boyutunda gerçekleşmiştir. Araştırmadan elde edilen bu sonuç, Turan'ın (2017) araştırma bulgularını destekler niteliktedir.

Araştırmadan elde edilen bulgulara göre, öğretmenlerin görüşleri doğrultusunda yenilikçi çalışma davranışlarını yüksek düzeyde sergiledikleri sonucuna ulaşılmıştır. Benzer şekilde Altıntaş Yüksel (2019), Çıtak (2017) ve Tüysüz (2019) araştırmalarında öğretmenlerin yenilikçi çalışma davranışları düzeyini yüksek olarak bulgulamışlardır. Diğer yandan Hsiao, Chang, Tu ve Chen (2011) ile Ismail ve Mydin (2019) öğretmenlerin yenilikçi çalışma davranışlarının orta düzeyde, Uzunbacak, Akçakanat ve Çarıkçı (2018) orta düzeyin biraz üzerinde, Töre (2019) ise çok yüksek düzeyde olduğunu belirlemiştir. Alt boyutlar açısından incelendiğinde ise öğretmenlerin yenilikçi çalışma davranışlarına ilişkin en yüksek ortalama, bilgisayar teknolojisinin kullanımına yönelik yenilikçi davranış ve en düşük ortalama ise uygulama odaklı çalışma davranışı boyutlarında gerçekleşmiştir.

COVID 19 küresel salgını nedeniyle ülkemizde uzaktan eğitime geçilmesi ve bu süreçte öğretmenlerin bilgisayar teknolojilerini sürekli kullanmak durumunda kalmaları sonucunda dijital becerilerinin daha da gelişmesi, konu ile ilgili özgüvenlerinin artması ve bunun da yenilikçi eğitim uygulamalarına yansımış olması muhtemel olarak 
düşünülmektedir. Diğer taraftan Töre (2017) turizm sektör çalışanlarının yenilikçi çalışma davranışlarını incelediği araştırmasında, çalışanların yenilikçi çalışma davranışının fikir destekleme faktörünün ortalama değerinin, fikir üretme ve uygulama faktörüne göre daha yüksek olduğunu belirlemiş ve çalışanların eyleme geçmekten daha fazla eylemi desteklemeyi tercih ettiklerini gösterdiği sonucuna ulaşmıştır. $\mathrm{Bu}$ doğrultuda araştırmada, uygulama odaklı çalışma davranışının, bilgisayar teknolojisinin kullanımına yönelik yenilikçi davranış ve yaratıcılık odaklı çalışma davranışı boyutlarına göre daha düşük bir ortalama vermesi, katılımcıların yeni fikir ve çözümlerini yönetici ve meslektaşlarını ikna ederek ve desteklerini de alarak uygulamaya geçirme becerilerini diğerlerine oranla daha az sergilediklerini ortaya koymakta ve Töre (2017) tarafından yapılan araştırmanın bulguları ile tutarlılık göstermektedir.

Araştırmanın sonuçları, öğretmenlerin görev yaptıkları okulların örgütsel zekâ düzeyleri toplamı ve yenilikçi çalışma davranış düzeyleri toplamı arasında pozitif yönlü yüksek düzeyde anlamlı bir ilişki bulunduğunu göstermektedir. Ayrıca araştırma ile öğretmenlerin görev yaptıkları okulların örgütsel zekâ düzeyinin yenilikçi çalışma davranışını yüksek düzeyde etkilediği sonucuna varılmıştır.

$\mathrm{Bu}$ araştırma, nicel desende tasarlanmış kesitsel türden bir tarama araştırmasıdır ve betimlenen değişkenler üzerinde bir seferde ölçüm yapılmıştır. Bu nedenle ilerideki araştırmalarda boylamsal araştırmaların kullanılması zamana bağlı değişimleri de ortaya çıkarabilir. Ayrıca ilerideki araştırmalarda nitel desenlerin kullanılması ile çok daha derinlemesine veri ve bilgi sağlanması mümkün olabilir. Bununla birlikte ilerideki araştırmaların farklı il ve ilçelerde, farklı eğitim kademeleri ve okullarda daha geniş örneklem hacmi ile gerçekleştirilmesi karşılaştırma olanağı açısından fayda sağlayabilir. 
EXTENDED ABSTRACT

\title{
The Impact of Organizational Intelligence Level on Teachers' Innovative Work Behaviour
}

\author{
Belgin Tura- Sait Akbaşlı \\ Hacettepe University
}

This study aimed at determining the effect of schools' organizational intelligence level on teachers' innovative work behaviors. Teachers of today's world must deal with the education and training processes with an innovative approach and innovatively design these processes by noticing the world outside the school, the changes taking place in the world, and the role of the school in this change process instead of limiting their minds only to the available curriculum. Teachers with innovative work behaviors deal with the characteristics and different needs of their students using new strategies and, therefore, help their students to develop their creativity in the learning and teaching processes. Innovation essentially includes intelligence. Without the creative spark of innovative genius or the intelligence of organizational systems that recognize and support innovation, finding new and useful solutions to problems becomes difficult. The development of organizational intelligence in schools increases the use of resources and competencies related to knowledge and learning, supports the development of teachers' innovation ability, and demonstrates them with innovative work behaviors. The determination of the effect of the organizational intelligence levels of the schools on the working behaviors of the teachers has strategic importance in terms of discovering the potentials of the schools, increasing the institutional capacities, and developing the teachers who are the most valuable elements of this capacity. With this research, it is considered that the effect of the organizational intelligence levels of schools on the innovative work behaviors of teachers, who are the main practitioners of education and training, will be revealed and the results will provide an idea to policymakers and educators who are responsible for establishing the foundations of the 21st-century education system. 
This study was a correlational study carried out in a survey model. The study group consisted of 328 branch teachers working in the public secondary schools and imam hatip middle schools affiliated to Ankara Sincan District Directorate of National Education (Ministry of National Education, Turkey) in the 2020-2021 academic year. The teachers in the study group were determined using an appropriate sampling method among non-random sampling methods. The data was collected by using the "Multidimensional Organizational Intelligence Scale" previously developed by Erçetin, Potas, and Açıalın (2001, 2004, 2007, 2009, 2010) and reorganized by Erçetin, Potas, and Açıkalın in 2015 and the "Innovative Work Behavior Scale (IWB)" developed by Dorenbosch, Engen, and Verhagen (2005) adapted by the researchers of this specific study (adapted to Turkish as "Yenilikçi Çalışma Davranışı Ölçeği"). Research data were collected using both face-to-face and online data collection tools. Within the scope of this study, the "Multidimensional Organizational Intelligence Scale" and the "Innovative Work Behavior Scale" were applied together, and the opinions of the teachers were converted into data.

Considering the analysis of the data, multiple linear regression analysis was conducted to determine whether the descriptive statistics and the organizational intelligence level of the schools where the teachers worked were significant predictors of the innovative work behaviors of the teachers or not. The collected data was analyzed using an available statistical package program. Three research questions were identified in this study that was designed to determine the effect of schools' organizational intelligence level on teachers' innovative work behaviors.

The first research question of this study was to determine the organizational intelligence levels of the schools where the teachers worked based on the opinions of the teachers. Based on the opinions of the teachers under this research question, it was determined that the organizational intelligence levels of the schools they worked in were high $(\bar{X}=3.87)$. When the Multidimensional Organizational Intelligence Scale was evaluated in terms of its sub-dimensions, it was seen that it was at a high level in all other sub-dimensions. Considering the sub- 
dimensions of the scale, the highest average was determined in taking immediate actions and producing instant reactions dimension $(\bar{X}=4.04)$ while the lowest average was determined in functioning flexibly and comfortably dimension $(\bar{X}=3.71)$. Considering the dimension of taking immediate actions and producing instant reactions, it can be expressed that the teachers thought that skills such as making decisions quickly and implementing them and developing actions by giving appropriate and correct responses to all kinds of situations affecting the school were realized more than other skills. However, considering the dimension of the functioning flexibly and comfortably, it can be expressed that teachers thought that skills such as being able to change the rules regarding the functioning of the schools they worked at, completing the bureaucratic works and procedures are performed at a level that does not reduce the pace of the organization, and the employees' being free to make choices in every subject were realized less than other skills.

The second research question of this study was to determine the innovative work levels of the teachers based on their opinions. In line with this research question, it was determined that they exhibited innovative working behaviors at a high level $(\bar{X}=3.98)$. On the other hand, the highest average of the sub-dimensions of the scale was observed in the innovative behavior towards the use of computer technology $(\bar{X}=4.15)$, and the lowest average was observed in the practice-oriented work behavior $(\bar{X}=3.87)$ dimensions. In this regard, it can be considered that teachers thought that they could demonstrate their ability to research, learn, and use new computer technologies and applications effectively in their studies more than others. However, it can be also considered that teachers thought that they could demonstrate their ability to put their new ideas and solutions into practice by convincing and getting the support of their administrators and colleagues less than others.

The third research question of the study was to determine whether the level of organizational intelligence predicted innovative work behaviors of teachers based on their opinions. It was determined that the level of organizational intelligence demonstrated a high and significant relationship with the organizational intelligence sub-dimensions and innovative work behaviors of the teachers $\left(\mathrm{R}=.843, \mathrm{R}^{2}=.705, \mathrm{p}<.01\right)$. In this 
regard, teachers' organizational intelligence level explained approximately $71 \%$ of the total variance regarding innovative work behavior. According to the standardized regression coefficient $(\beta)$, the importance levels of the independent variables on the level of innovative work were as follows; adapting to changing situations II, effective communication with stakeholders, adapting to changing situations I, taking immediate actions, and producing instant reactions, functioning flexibly and comfortably, using imagination and creativity dimension. When the t-test results regarding the significance of the regression coefficients were examined, it was determined that the dimensions of adapting to changing situations I, taking immediate actions and producing instant reactions, being flexible and comfortable in functioning, and being intuitive and prescient sub-dimensions were not significant predictors. In this regard, it can be stated that these dimensions do not have a significant effect on predicting innovative work behaviors. As a result, the findings of this study showed that there was a positive and highly significant relationship between the sum of the organizational intelligence levels of the schools where teachers worked at and the sum of the innovative work behavior levels. In addition to this, it was concluded that the organizational intelligence levels affected the innovative working behaviors of the teachers at a high level.

\section{Kaynakça / References}

Abstein, A., Heidenreich, S. ve Spieth, P. (2014). Innovative work behaviour: The impact of comprehensive HR system perceptions and the role of work-life conflict. Industry and Innovation, 21(2), 91-116.

Akbaşl1, S. (2010). The Views of elementary supervisors on teachers' competencies. Eurasian Journal of Educational Research, 39, 13-36.

Akbaşl1, S. (2007). Ortaöğretim okullarındaki okul aile birliklerinin görevlerini gerçekleştirme düzeyleri. (Doktora Tezi). Hacettepe Üniversitesi, Sosyal Bilimler Enstitüsü, Ankara.

Akbaşl1, S. ve Tura, B. (2019). Okul aile birlikleri okullara ne getirdi? Neyi Değiştirdi? OPUS Uluslararası Toplum Araştırmaları Dergisi, 14(20), 1747-1768. 
Albrecht, K. (2003). The power of minds at work. Organizational intelligence in action. New York: Amacom Books.

Allee, V. (1997). The knowledge evolution: Expanding organizational intelligence. Boston: Butterworth-Heinemann.

Altıntaş Yüksel, E. (2019). Sinıf öğretmenlerinin mesleki yenilikçilik eğilimleri ve öğretmenlik mesleğine ilişkin tutumları arasındaki ilişkinin incelenmesi (Doktora Tezi). Gazi Üniversitesi, Eğitim Bilimleri Enstitüsü, Ankara.

Azma, F., Mostafapour, M. ve Rezaei, H. (2012). The application of information technology and its relationship with organizational intelligence. Procedia Technology, 1, 94-97.

Blader, S. ve Tyler, T. (2009). Testing and extending the group engagement model: linkages between social identity, procedural justice, economic outcomes, and extrarole behavior. Journal of Applied Psychology, 94(2), 445-464.

Bos-Nehles, A., Bondarouk, T. ve Nijenhuis, K. (2017). Innovative work behaviour in knowledge-intensive public sector organizations: The case of supervisors in the netherlands fire services. The International Journal of Human Resource Management, 28(2), 379-398.

Büyüköztürk, Ş., Kılıç Çakmak, E., Akgün, Ö., Karadeniz, Ş. ve Demirel, F. (2019). Ĕ̆itimde bilimsel araştırma yöntemleri. Ankara: Pegem Akademi.

Çevik Tekin, İ. (2019). Psikolojik güçlendirmenin yenilikçi iş davranışına etkisinde örgütsel bağhllı̆̆ın aracillk rolü: Türkiye otomotiv üreticileri araştırması (Doktora Tezi). Selçuk Üniversitesi, Sosyal Bilimler Enstitüsü, Konya.

Çıtak, S. (2017). Duygusal zekâ ile yenilikçi iş anlayışı arasındaki iliş̧i üzerine bir araştırma Mersin İli örneği (Yüksek Lisans Tezi). Toros Üniversitesi, Sosyal Bilimler Enstitüsü, Mersin.

Çokluk, Ö., Şekercioğlu, G. ve Büyüköztürk , Ş. (2016). Sosyal bilimler için çok değişkenli istatistik SPSS ve LISREL uygulamaları. Ankara: Pegem Akademi.

Dorenbosch, L., Engen, M. ve Verhagen, M. (2005). On-the-job innovation: The impact of job design and human resource management through production ownership. Creativity and Innovation Management, 14(2), 129-141.

Erçetin, Ş., Çetin, B. ve Potas, N. (2007). Multi-dimensional organizational intelligence scale (Muldimorins). World Applied Sciences Journal, 2(3), 151-157.

Erçetin, Ş. (2001). Örgütsel zeka. Ankara: Nobel Yayın Dağıtım. 
Erçetin, Ş. (2004). Örgütsel zeka ve örgütsel aptallı. Ankara: Asil Yayın Dağıtım. Erçetin, Ş., Potas, N. ve Koç, İ. (2016). Organizational intelligence scale for business organizations in chaotic situations. Ş. Erçetin ve H. Bağc1 (Ed.). Handbook of Research on Chaos and Complexity Theory in the Social Sciences içinde (s.133-152). Hershey, ABD: IGI Global.

Erçetin, Ş., Potas, N., Hamedoğlu, M. ve Kısa, N. (2011). Using multidimensional organizational intelligence measurements to determine the institutional and managerial capacities of technical education institutions for girls. African Journal of Business Management, 5(27), 11256-11264.

Farr, J. ve Ford, C. (1990). Individual Innovation. M. West ve J. Farr (Ed.). Innovation and creativity at work: psychological and organisational strategies içinde (s.63-80). Chichester: John Wiley.

Glynn, M. (1996). Innovative genius: A framework for relating individual and organizational intelligences to innovation. Academy of Management Review, 21(4), 1081-1111.

Hsiao, H., Chang, J., Tu, Y. ve Chen, S. (2011). The impact of self-efficacy on innovative work behavior for teachers. International Journal of Social Science and Humanity, 1(1), 31-36.

İmamoğlu Akman, G. ve Akman, Y. (2019). Investigation of organizational intelligence level of schools according to teachers' opinion. Ş. Erçetin ve N. Potas (Ed.). Chaos, Complexity and Leadership 2017. Explorations of Chaos and Complexity Theory içinde (s.459-468). Cham, Switzerland: Springer.

Ismail, A. ve Mydin, A. (2019). The impact of transformational leadership and commitment on teachers' innovative behaviour. Advances in Social Science, Education and Humanities Research (ASSEHR) In 4th ASEAN Conference on Psychology, Counselling, and Humanities (ACPCH 2018) (s. 426-430). Atlantis Press.

Janssen, O. (2000). Job demands, perceptions of effort-reward fairness and innovative work behaviour. Journal of Occupational and Organizational Psychology, 73(3), 287-302.

Kalkan, V. (2005). Organizational intelligence: Antecedents and consequences. Journal of Business E Economics Research, 3(10), 43-54.

Kheng, Y., Mahmood, R. ve Beris, S. (2013). A conceptual review of innovative work behavior in knowledge intensive business services among 
knowledge workers in Malaysia. International Journal of Business, Humanities and Technology, 3(2), 91-99.

Liebowitz, J. (2000). Building Organizational intelligence. A knowledge management primer. Boca Raton, Florida: CRC Press.

Mertler, C. ve Vannatta Reinhart, R. (2017). Advanced and multivariate statistical methods. practical application and interpretation $(6$ b.). New York: Taylor \& Francis.

Messmann, G. ve Mulder, R. (2011). Innovative work behaviour in vocational colleges: understanding how and why innovations are developed. Vocations and Learning, 4, 63-84. doi: doi.org/10.1007/s12186-010-9049-y

Neuman, W. (2016). Toplumsal Araştırma yöntemleri (Cilt 2). (Çev. S. Özge) Ankara: Yayınodası.

Neyişci, N. (2015). Sosyal ă̆ etkileşiminin örgütsel zeka düzeyine etkisi. (Doktora Tezi). Hacettepe Üniversitesi, Eğitim Bilimleri Anabilim Dalı Eğitim Yönetimi, Teftişi, Planlaması ve Ekonomisi Bilim Dalı, Ankara.

Neyişci, N., Potas, N. ve Erçetin, Ş. (2018). Örgütsel zeka algısı ve ortak değişkenlerin etkisi: ANCOVA analizi ile incelenmesi. Sakarya University Journal of Education, 8(4), 300-318.

Potas, N., Erçetin, Ş. ve Bayrakçeken, S. (2009). Organizational Intelligence Scale II (University Version) and its application (The Example of Kazım Karabekir Faculty of Education, Atatürk University. Ş. Erçetin (Ed.). Organizational Intelligence in Question içinde (s.23-58). Charleston, South Carolina: BookSurge Publishing.

Potas, N., Erçetin, Ş. ve Koçak, S. (2010). Multi dimensional organizational intelligence measurements for determining the institutional and managerial capacity of girls' technical education institution (Diyarbakır, Şanliurfa and Konya/Turkey). African Journal of Business Management, 4(8), 1644-1651.

Sanders, K., Moorkamp, M., Torka, N., Groeneveld, S. ve Groeneveld, C. (2010). How to support innovative behaviour? The role of $\operatorname{lmx}$ and satisfaction with hr practices. Technology and Investment, 1(1), 59-68.

Scott, S. ve Bruce, R. (1994). Determinants of innovative behavior: A path model of individual innovation in the workplace. Academy of Management Journal, 37(3), 580-607.

Senge, P. (2007). Beşinci disiplin. (Çev. A. İldeniz ve A. Doğukan) İstanbul: Yapı Kredi Yayınları. 
Töre, E. (2017). Entelektüel sermayenin yenilikçi davranışına etkisinin bilgi paylaşımı, öz-yeterlilik ve iç denetim odağı perspektifinden incelenmesi üzerine bir araştırma (Doktora Tezi). İstanbul Üniversitesi, Sosyal Bilimler Enstitüsü, İstanbul.

Töre, E. (2019). Öğretmenlerin yenilikçi iş davranışı düzeylerinin belirlenmesi ve çeşitli değişkenlere göre incelenmesi. Turkish Studies - Educational Sciences, 14(4), 1761-1773.

Tura, B. ve Akbaşlı, S. (2021). Öğretmen yenilikçiliğini etkileyen faktörler. Uluslararası Temel Eğitim Çalışmaları Dergisi, 2(1), 15-28.

Turan, S. (2017). Okul yöneticilerinin kuantum liderlik davranışlarının örgütsel zeka düzeyine etkisi (Zonguldak İli Örneği). (Doktora Tezi). Hacettepe Üniversitesi, Eğitim Bilimleri Anabilim Dalı Eğitim Yönetimi, Teftişi, Planlaması ve Ekonomisi Bilim Dalı, Ankara.

Tüysüz, H. (2019). Eğitim yöneticilerinin örgütsel destek algısl, örgütsel hafiza ve yenilikçi iş davranışları arasındaki ilişkinin incelenmesi (Doktora Tezi). Marmara Üniversitesi, Eğitim Yönetimi ve Denetimi Bilim Dall, İstanbul.

Uzunbacak, H., Akçakanat, T. ve Çarıkçı, İ. (2018). Lider-üye etkileşimi ile yenilikçi iş davranışı arasındaki ilişkide algılanan örgütsel desteğin ve işe adanmışlığın rolü. 6. Örgütsel Davranış Kongresi Bildiriler Kitabı içinde (s.17-29). Isparta: Süleyman Demirel Üniversitesi.

Van de Ven, A. (1986). Central problems in the management of innovation. Management Science, 32(5), 590-607.

Veryard, R. (2018). Building organizational intelligence. Leanpub Book. Erişim adresi https://leanpub.com/orgintelligence. Erişim tarihi: 17 Eylül 2020.

\section{Kaynakça Bilgisi / Citation Information}

Tura, B. ve Akbaşlı, S. (2021). Örgütsel zekâ düzeyinin öğretmenlerin yenilikçi çalışma davranışları üzerindeki etkisi. OPUSUluslararası Toplum Araştırmaları Dergisi, 18(43), 6790-6805. DOI: 10.26466/opus.937986. 